\section{References}

Addison, G. M., et al. (1972). Fournal of Clinical Pathology, 25, 326 Jacobs, A., et al. (1972). British Medical fournal, 4, 206.

Jones, P. A. E., et al. (1973). British fournal of Cancer, 27, 212.

Parry, D. H. (1974). Unpublished data.

Pinkel, D. (1971). Fournal of the American Medical Association, 216, 648.

Medical Research Council (1963). British Medical fournal, 1, 7.
Siimes, M. A., Addiego, J. E., and Dallman, P. R. (1974). Blood, 43, 581. Summers, M., Worwood, M., and Jacobs, A. (1974). British fournal of Haematology, 28, 19.

Walters, G. O., Miller, F. M., and Worwood, M. (1973). Fournal of Clinical Pathology, 26, 770 .

White, G. P., et al. (1974). Nature, 250, 584.

Worwood, M., et al. (1974). British fournal of Haematology, 28, 27.

Young, D. S., and Hicks, J. M. (1965). Fournal of Clinical Pathology, 18, 98

\title{
Incidence of Early Post-operative Iliofemoral Thrombosis
}

\author{
J. P. BOLTON, V. J. HOFFMAN
}

British Medical fournal, 1975, 1, 247-249

\section{Summary}

The Doppler ultrasound probe was used to study 138 patients after major surgery to assess the incidence of iliofemoral thrombosis in the early postoperative period. The patients were simultaneously studied with the ${ }^{125}$ Ifibrinogen uptake test. The accuracy of the ultrasonic technique was assessed concurrently by comparing its results with those of ascending phlebography in a separate group of patients.

The ultrasound probe detected thrombus proximal to the calf but was inaccurate in locating its exact site. Of the 138 patients studied postoperatively 28 developed calf vein thrombosis detected isotopically, but there was no evidence of iliofemoral thrombosis in any patient. Thus, spontaneous iliofemoral thrombosis in the early postoperative period is rare.

\section{Introduction}

The technique of using human fibrinogen labelled with radioactive iodine to detect postoperative deep vein thrombosis (Hobbs and Davis, 1960; Atkins and Hawkins, 1965) has led to a greater understanding of the incidence and natural history of the condition (Flanc et al., 1968; Kakkar et al., 1969). The technique reliably detects thrombosis in the calf and popliteal veins (Negus et al., 1968). It is not so accurate in diagnosing thrombus in the proximal femoral vein, however, and cannot detect it in the iliac veins, and it is from these areas that dangerous pulmonary emboli arise. It has been suggested (Sevitt, 1962; Mavor and Galloway, 1969; Mavor et al., 1972) that such proximal thrombi do not necessarily arise in association with and as a result of distal calf vein thrombosis, and if this is so then ${ }^{125} \mathrm{I}$-fibrinogen studies do not detect the patients most at risk of developing a dangerous pulmonary embolus.

This study was done to determine the incidence of iliofemoral thrombosis in the early postoperative period by studying patients simultaneously with the Doppler ultrasound probe for the iliofemoral segment and the ${ }^{125}$ I-fibrinogen uptake test for the calf and popliteal region (study 2). At the same time we assessed the accuracy of the Doppler ultrasound probe by comparing its findings with those of ascending phlebography in patients presenting with signs and symptoms suggestive of a pulmonary emboius or a deep vein thrombosis (study 1 ). \footnotetext{
Department of Surgical Studies, Middlesex Hospital, London
W1P 7PN

J. P. BOLTON, M.B., F.R.C.S., Surgical Registrar

V. J. HOFFMAN, M.B., F.R.C.S., Surgical Registra
}

\section{Technique}

The ultrasound machine used was a Sonicaid D205 with a $2-\mathrm{MHz}$ output. The technique of using the machine was based on that described by Evans and Cockett (1969). The method relies on detecting augmentation or " $A$ " waves over the major veins of the lower limb and pelvis when the limb is compressed at a lower level. The transducer is placed successively over the superficial femoral, common femoral, and external iliac veins and the inferior vena cava two inches $(5 \mathrm{~cm})$ above and to the right of the umbilicus, and A waves are detected after compression of the limb at varying points distally. By defining the highest point in the limb at which the $\mathrm{A}$ wave is absent or abnormal on compression it is theoretically possible to determine not only the presence of but also the upper limit of a thrombus. The method cannot be expected to localize the exact extent of thrombus in the calf and popliteal region. For instance, if with the transducer over the superficial femoral vein compression of the calf does not produce an A wave but compression of the lower thigh produces a normal one there may be either extensive thrombus confined to the calf or a thrombus in the popliteal vein at the level of the knee joint.

In the postoperative patients we found it impossible to detect A waves in the inferior vena cava because abdominal wounds and associated drains and dressings prevented satisfactory positioning of the transducer. The patency of the iliac veins was, therefore, assessed by studying spontaneous or " $S$ " waves (Sigel, 1968) at the level of the external iliac veins. $S$ waves are produced by the alteration in flow in the major veins caused by changes in the intrathoracic pressure in inspiration and expiration. The $2-\mathrm{MHz}$ machine allows the flow in the external iliac veins to be detected easily, and we found that the $S$ waves are heard better over this vessel than over the common femoral vein. If the patient takes deep breaths the $S$ waves are accentuated. If $S$ waves are detected in the external iliac veins this implies that the flow in these veins is being directly influenced by changes in the intrathoracic pressure and, therefore, there can be no major obstruction in the inferior vena cava or the common iliac vein on the same side.

We tried to localize the upper limit of the thrombus to one of three segments; iliac, femoral, or popliteal/calf. The detection of thrombus below the external iliac vein was based on A wave abnormalities and above the external iliac vein on the alteration in $S$ waves heard at that level.

In the postoperative patients potassium iodide $100-150 \mathrm{mg}$ was given by mouth or intravenously the day before operation and continued daily for two weeks. Human fibrinogen from a pool of screened donors was iodinated at the Radiochemical Centre, Amersham, and $100 \mu \mathrm{Ci}$ was given within three hours of the completion of operation. The patients' legs were studied with the Pitman isotope localization monitor one, two, four, and six days after operation and for longer if a deep vein thrombosis was present. The method of counting and the criteria for diagnosis were as described by Negus et al. (1968) except that a persistent $20 \%$ difference between adjacent points or an 
equivalent point on the opposite limb was regarded as necessary for the diagnosis of deep vein thrombosis, (Pai and Negus, 1971).

\section{Study 1}

\section{PATIENTS AND METHODS}

The findings with the Doppler ultrasound probe were compared with those on ascending phlebography in 43 patients-27 women and 16 men-presenting with signs and symptoms suggesting a deep vein thrombosis or a pulmonary embolus. The patients were suffering from various conditions and none had just had an operation. A total of 76 legs were examined using both techniques, and ascending phlebography was carried out within a short time of the ultrasound examination, in all cases within 24 hours.

\section{RESULTS}

On ultrasonic examination 42 of the 76 limbs were considered to be normal. Phlebography confirmed this in 32, but in 10 legs a thrombus was shown to be present in the popliteal/calf segment; in nine the thrombus was confined to the calf and in one there was extension to the low popliteal vein. No limb normal on ultrasound examination had phlebographic evidence of thrombus in the femoral or iliac veins (see table).

In 34 limbs the ultrasound examination indicated the presence of a thrombus, and in 27 this was confirmed by phlebography. Ultrasound did not accurately localize the extent and upper limit of the thrombus, however, and in eight of the 27 limbs phlebography showed that the ultrasound examination was misleading as to the extent of the thrombus. In particular, in four limbs in which a thrombus in the popliteal/calf segment was diagnosed ultrasonically there was a thrombus in the femoral vein.

Using $S$ waves to assess the iliac veins five limbs were diagnosed as having a thrombus in the iliac segment, which was incorrect in three. Out of three limbs with phlebographic evidence of thrombus in the iliac veins only two had $S$ wave abnormalities, but in all three the $\mathrm{A}$ waves were abnormal at some point in the leg.

\section{Study 2}

\section{PATIENTS AND METHODS}

A total of 138 patients who had undergone major surgery were studied after their operation with the ${ }^{125}$ I-fibrinogen uptake test and the Doppler ultrasound probe. Both tests were carried out as described on days one, two, four, and six by different observers who were unaware of the results of the other test.

\section{RESULTS}

Of the 138 patients (276 legs) 75 were men and 63 were women. Deep vein thrombosis was diagnosed in 37 legs by the ${ }^{125} I$-fibrinogen uptake test. In all cases the thrombus was detected in the calf and there was no evidence of extension to the popliteal or superficial femoral vein during the period of screening. In 20 legs deep vein thrombosis was detected on the first or second day after operation, in 10 on the fourth day, and in seven on the sixth day.

No patient developed signs of an iliofemoral thrombosis or pulmonary embolus during the period of screening. One patient who was normal on ultrasound screening and fibrinogen scanning up to the sixth day after operation developed a left iliofemoral thrombosis on the 17th day after the development of a large pelvic abscess. Another patient with a calf thrombosis developed extension into the popliteal vein on the 11 th day after operation. Both were confirmed by ascending phlebography.

Using the ultrasound probe the A waves were studied in all legs. In 212 legs $A$ waves were studied up to the external iliac vein from the first day of screening. In 64 legs the external iliac veins were inaccessible on the first day and examination was carried out only up to the common femoral vein, but on subsequent days a full examination of the $\mathbf{A}$ waves up to the external iliac vein was possible. In the whole group four legs had abnormal A waves, in each case indicating a thrombus in the popliteal/calf region. One was noted on day one, one on day two, and two on day four. In one limb the presence of a thrombus was confirmed by the ${ }^{125} \mathrm{I}$-fibrinogen uptake test, but in the other three the fibrinogen test was negative.

In the first 21 patients ( 42 legs) an attempt was made to study the external and common iliac veins by assessing the $A$ waves over the inferior vena cava on compression of the thigh. This particular part of the ultrasound screening test could not be carried out immediately after operation, and in most of these patients $A$ waves were not heard over the inferior vena cava during the period of screening. In the remaining 117 patients (234 legs) the $S$ waves were used. On the first day after operation access to the external iliac veins was not possible in 64 legs, and the $S$ waves were assessed over the common femoral veins; in 22 the $S$ waves were absent. On subsequent days the external iliac veins were accessible and in all these legs the $S$ waves were normal from the seccond day. In 178 legs the $S$ waves were assessed at the external iliac level from the first day. In eight the $S$ waves were absent on the first day but were present and normal on subsequent testing.

\section{Discussion}

Evans (1970) found that in 60 cases of proved deep vein thrombosis in the popliteal vein and above the ultrasound test detected $95 \%$ of the thrombi. Holmes (1973) using ultrasound to study the femoral and popliteal veins only detected a thrombus in all 17 cases in which phlebography confirmed its presence. In our first study a thrombus was detected in $13(93 \%)$ out of 14 legs in which it was present proximal to the calf.

The detection of thrombus with the Doppler ultrasound probe is based on partial or total occlusion of the major venous channels. It will not therefore detect small calf vein thrombi. Such failure has been reported previously (Evans, 1970, Milne et al., 1971) and was confirmed by our false-positive and falsenegative results. Nine out of 42 limbs thought not to contain thrombi on ultrasound screening had small calf vein thrombi, and six out of 24 limbs thought to have thrombi in the popliteal/ calf segment had no thrombi demonstrable on phlebography.

The ultrasound probe accurately detected a thrombus if it was present in the iliofemoral segment-all 11 limbs with iliofemoral thrombosis were positive on ultrasonic examination. It was also accurate in confirming the absence of thrombus from the iliofemoral segment. The test was inaccurate in localizing the exact site and extent of a thrombus, however: of eight limbs with a thrombus in the femoral vein in only three was the correct site determined by the ultrasound test (see table).

Comparison of Ultrasonic and Phlebograghic Findings in 76 Limbs

\begin{tabular}{|c|c|c|c|c|c|c|}
\hline \multirow{2}{*}{$\begin{array}{l}\text { Ultrasonic } \\
\text { Findings }\end{array}$} & \multirow[b]{2}{*}{ Total } & \multicolumn{5}{|c|}{ Phlebographic Findings } \\
\hline & & $\begin{array}{c}\text { No } \\
\text { Thrombus }\end{array}$ & C. & P. & F. & I. \\
\hline $\begin{array}{l}\text { No Thrombus } \\
\text { P./C. } \\
\text { F. } \\
\text { I. }\end{array}$ & $\begin{array}{l}42 \\
24 \\
5 \\
5\end{array}$ & $\begin{array}{c}32 \\
6 \\
1\end{array}$ & $\begin{array}{c}9 \\
12 \\
1 \\
1\end{array}$ & $\begin{array}{l}1 \\
2\end{array}$ & $\begin{array}{l}4 \\
3 \\
1\end{array}$ & $\frac{1}{2}$ \\
\hline Total & 76 & 39 & 23 & 3 & 8 & 3 \\
\hline
\end{tabular}

P./C. = Thrombus in popliteal/calf segment. F. = Thrombus in femoral vein. I. $=$ Thrombus in iliac veins.

We attempted to assess the patency of the inferior vena cava and common iliac vein by recording changes in the $S$ waves detected over the external iliac vein. This technique did not prove reliable, as Sigel (1970) found also. Nevertheless, by studying the A waves to the level of the external iliac veins we were able to detect a thrombus in all limbs in which it was present in the iliofemorol segment and we consider this technique provides the maximum amount of accurate information that can be gained with the Doppler ultrasound probe.

From our results and those of previous reports it is concluded that with important limitations, the Doppler 
ultrasound probe is a valuable tool for detecting thrombi in the deep veins of the lower limb. If the limb is normal on ultrasonic examination there is no thrombus present proximal to the calf and in most cases no thrombus present at all. But if the vein is abnormal on ultrasonic examination the limb probably contains a thrombus though its extent is not accurately indicated by this form of examination. Accordingly, a positive ultrasound result is an indication for phlebography.

These conclusions on the scope and accuracy of the Doppler ultrasound probe may be applied to the results obtained in the postoperative group. The A waves were studied up to the external iliac vein in 212 legs throughout the period of study. In 64 legs the common femoral vein was the highest point studied on the first day after operation, but on subsequent days full testing to the external iliac level was possible. Theoretically, therefore, abnormalities might have been present in the iliac veins on the first day which were missed because of incomplete screening. The normal findings a day later, however, indicate that a thrombus, had it been present, must have embolised or spontaneously lysed within 24 hours, which is unlikely. It is reasonable therefore to assume that though the ultrasound screening was incomplete in 64 legs on the first day the overall screening was adequate to have detected iliofemoral thrombus had it been present.

In 272 legs the ultrasound showed nothing abnormal and it may be concluded that no thrombus was present in the iliofemoral ultrasonic examination in those legs. Four legs were found to be abnormal on ultrasonic examination, but in only one leg was a calf vein thrombus confirmed by the ${ }^{125} \mathrm{I}$-fibrinogen uptake test. In the remaining three legs the absence of thrombus was shown by ascending phlebography in two and the third had evidence of a previous deep vein thrombosis. Hence we conclude that no patient in this group developed a thrombus in the iliofemoral segment during the period of screening despite thrombosis developing in the calf veins of 37 legs. Our results lend no support to the suggestion that the development of dangerous iliofemoral thrombosis in the early postoperative period in the absence of calf vein thrombosis is a common occurrence.

In two patients thrombosis developed or extended proximal to the calf after the period of screening was completed. In both cases the postoperative course was complicated, which illustrates that in patients with a complicated course this type of thrombosis may develop late.

We thank the surgeons of the Middlesex Hospital who allowed us to study patients under their care. We are particularly indebted to Professor L. P. LeQuesne for his advice and support during the study and in preparing the text.

\section{References}

Atkins, P., and Hawkins, L. A. (1965). Lancet, 2, 1217.

Evans, D. S. (1970). British fournal of Surgery, 57, 726.

Evans, D. S., and Cockett, F. B. (1969). British Medical fournal, 2, 802.

Flanc, C., Kakkar, V. V., and Clarke, M. B. (1968). British fournal of Surgery, 55, 742 .

Hobbs, J. T., and Davies, J. W. L. (1960). Lancet, 2, 134.

Holmes, M. C. G. (1973). Medical Fournal of Australia, 1, 427.

Kakkar, V. V., et al. (1969). Lancet, 2, 230.

Mavor, G. E., and Galloway, J. M. D. (1969). British fournal of Surgery, $56,45$.

Mavor, G. E., et al. (1972). Lancet, 1, 661.

Milne, R. M., et. al. (1971). Lancet, 2, 445.

Negus, D., et. al. (1968). British fournal of Surgery, 55, 835.

Pai, B. Y., and Negus, D. (1971). Lancet, 2, 1098.

Sevitt, S. (1962). American fournal of Medicine, 33, 703.

Sigel, B., et. al. (1968). Surgery, Gynecology and Obstetrics, 127, 339.

Sigel, B., et. al. (1970). Archives of Surgery, 100, 535.

\section{MEDICAL MEMORANDA}

\section{Mixed Connective Tissue Disease with Digital Gangrene}

\author{
D. KITCHINER, J. EDMONDS, C. BRUNEAU, \\ G. R. V. HUGHES
}

British Medical fournal, 1975, 1, 249-250

In 1969 Sharp et al. proposed the term "mixed connective tissue disease" for an apparently distinct rheumatic disease syndrome with features of systemic lupus erythematosus, progressive systemic sclerosis, and dermatomyositis but characterized by a good prognosis and by the finding of a specific antinuclear antibody in the serum (Sharp et al., 1969). The patient described here showed many of the characteristics of this syndrome, a distinctive feature being the severity of Raynaud's phenomenon, leading ultimately to gangrene of multiple digits.

\footnotetext{
Department of Medicine, Royal Postgraduate Medical School, London W12 0HS

D. KITCHINER, M.R.C.P., Senior House Officer

J. EDMONDS, M.R.A.c.P., Senior Registrar

G. R. V. HUGHES, M.D., M.R.C.P., Consultant Physician
}

After 12 years of follow-up there was no evidence of renal disease. It is felt that the recognition of distinct syndromes within the general heading of systemic lupus erythematosus is justified to assess prognosis.

\section{Case Report}

The patient, a housewife, presented in 1960 at the age of 22 years with joint pains and morning stiffness. The following year she developed Raynaud's phenomenon, recurrent abdominal pain, and pleuritic chest pain. She was first seen at Hammersmith Hospital in January 1962 with active synovitis of her hands and knees and generalized lymphadenopathy. Investigations showed: haemoglobin $10.9 \mathrm{~g} / 100 \mathrm{ml}$ and E.S.R. $60 \mathrm{~mm} / \mathrm{hr}$. Tests were positive for rheumatoid factor (Laxtex fixation test) and antinuclear factor and negative for L. E. cells, and the Wassermann reaction was negative. A diagnosis of systemic lupus erythematosus was made.

Two months later she had further pleuritic chest pain and prednisone $5 \mathrm{mg}$ three times a day was begun. Over the next two years Raynaud's phenomenon became severe, resulting in progressive sclerodactyly, infection, ischaemic necrosis, and amputation of the tips of most of her fingers. Bilateral cervical and later transthoracic sympathectomies were performed with only transient improvement.

Apart from the severe Raynaud's phenomenon and its sequelae she remained well on prednisone $7.5 \mathrm{mg}$ daily until January 1974 when she presented with weakness and fatigue.

On examination she was found to be pale and had the digital changes shown in fig. 1 , with sclerodactyly and amputation of most of her fingertips. The rest of her skin was normal. There was no telangiectasia or other evidence of scleroderma, and she had no muscle weakness or tenderness. 